Vol. 8, Issue 6, June 2019

\title{
IOT Based Dam Monitoring System
}

\author{
S.Rajapriya ${ }^{1}$, A.Abinaya ${ }^{2}$, V.Subashini ${ }^{3}$ \\ Assistant Professor, Department of ECE, K.Ramakrishnan College of Engineering, Trichy, India ${ }^{1,2,3}$
}

\begin{abstract}
Monitoring Dams safety and water management is extremely important considering both the situations like water scarcity and excess of water. It is of crucial importance and needs to develop information system based on existing system allowing utilization of intelligent sensors network. Basic idea is to describe possibilities of IoT applications in Dam Safety and water management. Here the entire dam and the main pipeline is sensed $24 \times 7$ through various sensors. These wireless sensor nodes connected with each other and transmits the data to a gateway. Common storage space 'CLOUD' stores and provides on line information to the observer. Employing an IoT for the said purpose will definitely help saving the most precious natural resource the water. Here in this paper an attempt is made proposing an electronic circuit design employing an Internet of Things concept for the purpose. Ultrasonic sensor is used to find the crack in dam and vibration sensor is used to find any abnormal changes in dam due to natural disaster.
\end{abstract}

Keywords: Crack, Dam, Microcontrollers, Sensors, Interface panel

\section{INTRODUCTION}

Dam plays a major role in our life as they are used for purpose such as irrigation flood control and mainly generation of electricity. There are approximately 4200 major/minor dams in India. When it comes to dams, there are various parameter to be measured. Now a day's dam authorities are facing problems regarding the dam and the weather parameters monitoring as most of the small dams are still using manual observation and older technique of transmission system. Manual observation and transmission result in considerable time lag between data observed, its transmission and for decision taking. Also, this causes loss of real time data and sometimes become the reason for upcoming disaster. When it specifically towards water level measurement for water discharge to generation and irrigation. It has to be measure at least one time in 24 hours. Most of dam's measure water level manually as it not convenient to keep continues monitor on the change of water level. There is a need to look forward for an advance technology. So, we are about to design such a technology in which we will place a reflector on the water surface on which the transmitter will direct a beam on the reflector and by certain logics, the water level can be determined.

\section{TECHNOLOGY}

Proposed system consists of various sensors like water flow sensor, water level sensor, vibration sensor and ultrasonic sensor. These sensors takes actual physical quantity and this transmitter and according to these data information is given to the microcontroller through wireless LCD display shows the quantity like vibration, water level low or high etc. We have another advance options to opening of dam gates according to water level. IoT used for transmission of this information over long distance by using IoT wireless technology. At another end IoT is used to collect this information and given to PC and we develop one IOT Application to update this information on Internet webpage for public access for security purpose of nearer area. System will be generating immediate alert for sudden changes in water like rapid hike in water level or major change in vibration values in android application. It is very easy to use and definitely useful for preventing floods and other harms due to rapid changes in Dam water. Therefore, water level indicator designing is one of the technological advancement to transmit data and received by authority for controlling. If water level increases to dangerous level, the systems also give an alert to authority to take immediate action.

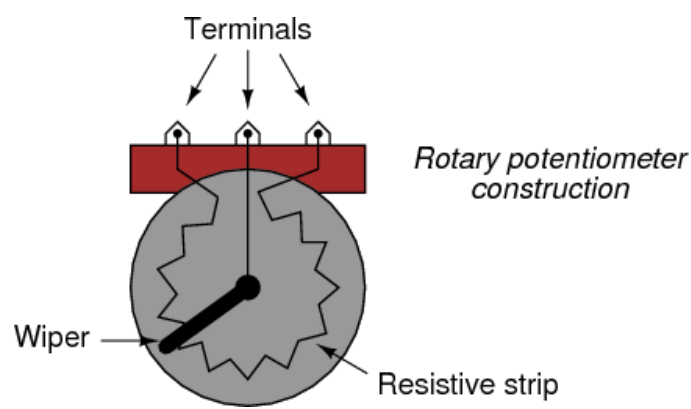

Fig 1. Construction and working 
Vol. 8, Issue 6, June 2019

The system can be used at the river-banks, low-lying areas, dam and the village far from town. In proposed system by making use of IOT the real time water monitoring system will be developed for measuring water level and the contamination in water. Statistics as well as previous history of water flow values of water and changes in water level over the time suitable for the system Selection of Sensors and other components with Correspondence to the site of Implementation which includes Mechanical as Electrical Parameters.

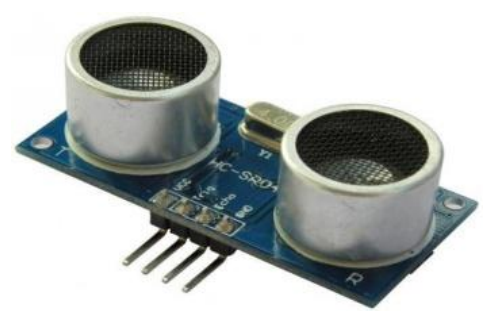

Fig 2. HC-SR04(Ultrasonic sensor)

\section{BLOCK DIAGRAM}

The hardware component includes Power supply, waterflow sensor, ultrasonic sensor, vibration sensor, level converter, Driver, Relay, Motor, LCD display, Buzzer, Load cell, switches. The software used here is MPLab IDE.

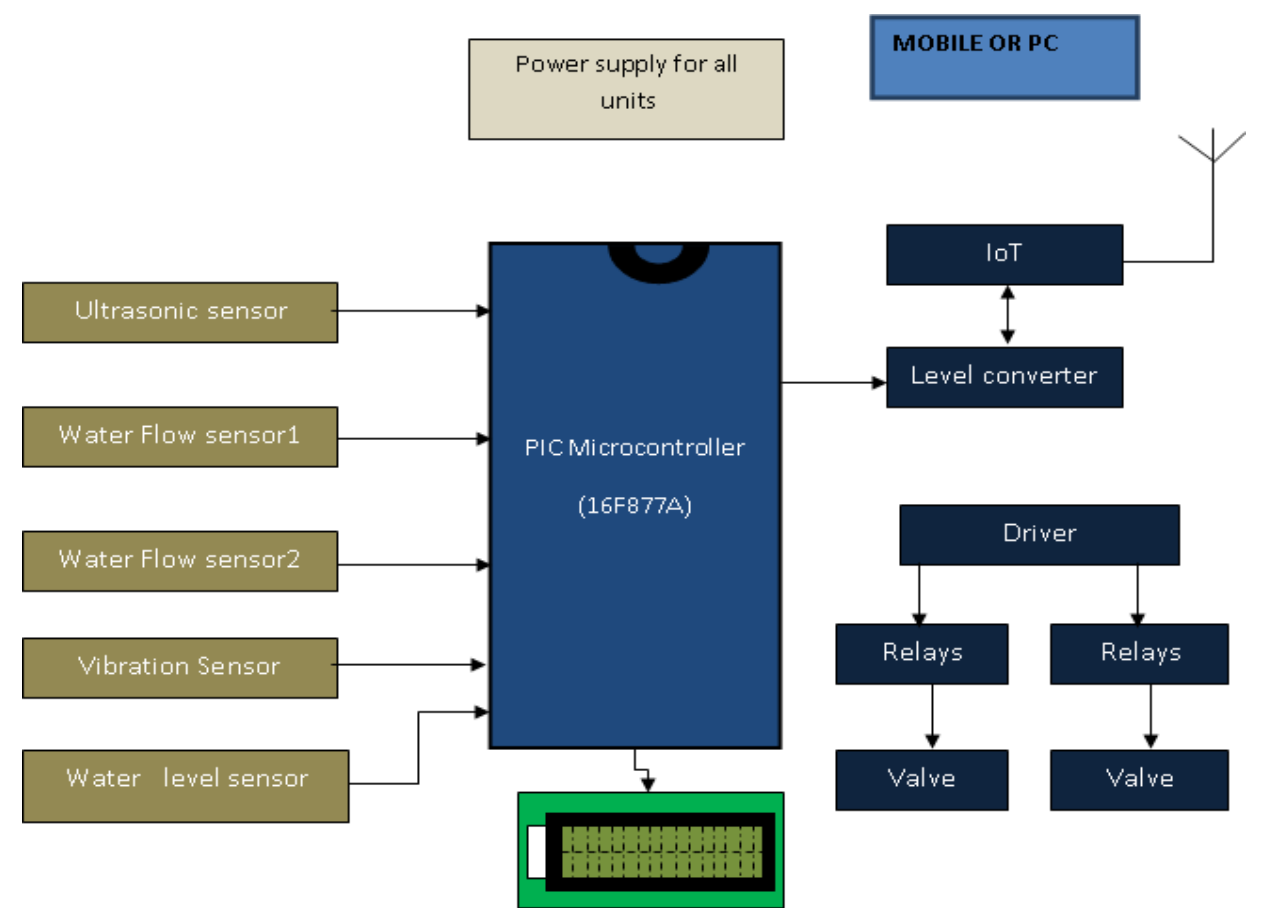

Fig 3. Block Diagram of Dam Monitoring System

\section{EXISTING SYSTEM}

The processing difficulty of the detection of crack completely depends on the size of the image. Recent digital cameras have the image resolution beyond 10 megapixels. This increase in resolution enables the procurement of detailed images of concrete surfaces. By using the commercial purpose cameras a wide range of a concrete surface can be acquired in a single shot. For less expensive applications, a image of wide range can be used for the practical crack detection.

\section{SYSTEM DESIGN}

The dam monitoring system is designed by DC motor using the relay and the driver circuit. The ultrasonic sensor is used to measure the distance and to find the crack in dam. vibration sensor is used to find any abnormal changes in dam due to natural disaster. signal conditioning unit is used to manipulate an analog signal. Relay can be used to control several circuits by one signal. 


\title{
International Journal of Advanced Research in Computer and Communication Engineering
}

\author{
Vol. 8, Issue 6, June 2019
}

This can be done by the interfacing of DC motors and the sensors to the microcontroller PIC16F877A

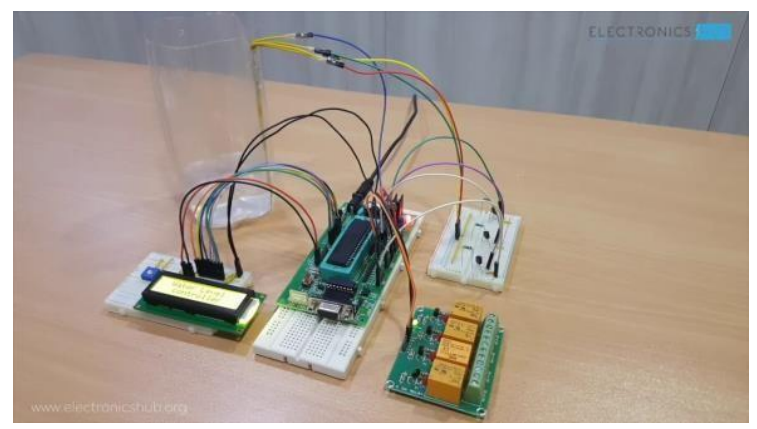

Fig 4.Top view

VI.

CONCLUSION

This system will help dam authority to know the dam parameters without checking manually by the mean of Display and Web portal. It is based on IoT Hence the speed of data transmission is high and probability of losing real time will be less. This system is reliable and cheaper to install in every dam and a web portal can provide detailed parameters of all dams in India. In this project the possible application of latest technologies such as internet of things, sensor ml and wireless sensors networks with software for dam safety management. Combination of these technologies and software improves functionality of dams. sensor technology, computer technology and network technology are advancing together while the demand grows for ways to connect information systems with the real world.

\section{REFERENCES}

[1]. R.Balamurugan, N.R.Nagarajan, “Automotic robotic ARM using hand gestures”, IJERT, March'2017.

[2]. P.Jiang, H. Xia, Z. He, and Z. Wang, "Design of a water environment monitoring system based on wireless sensor networks," Sensors, vol. 9, no. 8, pp. 6411-6434, 2009.

[3]. Y. Kong \& P. Jiang, "Development of data video base station in water environment monitor oriented wireless sensor networks," In Proceedings of the International Conference on Embedded Software and Systems Symposia, 29-31 July 2008, Sichuan, China, 2008, pp. 281-286.

[4]. O. Postolache, P. Girao, J. Pereira, H. Ramos, "Wireless water quality monitoring system based on field point technology \& kohonen maps," in Canadian Conference on Electrical \& Computer Engineering, IEEE CCECE 2003, 4-7 May2003, Montreal, Canada, vol.3, 2003, pp.1873-1876

[5]. Nikhil Dhandre M, Kamalasekaran PD, Pooja P (2016) Dam Parameters Monitoring System. IEEE.

[6]. Rohit S, Surabhi R, Shalaka, Rahul C (2014) Smart White Cane - An Elegant and Economic Walking Aid. AJER 3: 84-89.

[7]. Analyn Yumang N, Charmaine Paglinawan C, Arnold Paglinawan C, Glenn Avendano O, Jose Angelo Esteves C, et.al. (2017) Real-Time Flood Water Level Monitoring System with SMS Notification. IEEE.

[8]. Nitin Vijaykumar S , Vilas Malappa J (2017) Performance Measurement of Laser Communication Prototype in Free Space for Water Dam using AT mega328 and Comparison with ZigBee Technology. IEEE

[9]. Thinagaran Perumal, Md Nasir Sulaiman, Leong.C.Y, “Internet of Things (IoT) Enabled Water Monitoring System” in 2015 IEEE 4th Global Conference on Consumer Electronics(GCCE), Catrino, Malaysia.

[10]. Z. Wang, Q. Wang, and X. Hao, "The design of the remote water quality monitoring system based on wsn," in 2009 5th International Conference on Wireless Communications, Networking and Mobile Computing, 24-26 Sept. 2009, Beijing, China, 2009 , pp. 1-4.

\section{BIOGRAPHIES}

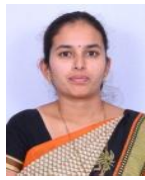

S.Rajapriya, Assistant Professor of Department of ECE in K.Ramakrishnan College of Engineering. She completed her B.E in ECE Department at Periyar Maniammai College of Technology for Women. She completed her M.Tech in Communication Systems at PRIST University. Her Research Interests are Antenna and wave propagation, Transmission lines \& Waveguides, RF \& Microwave engineering and Digital Image Processing.

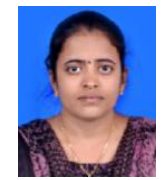

A.Abinaya, is an Assistant Professor/ ECE Department in K.Ramakrishnan College of Engineering, Trichy, Tamilnadu. She is pursuing Ph.D in Anna University, Tamilnadu. She completed her BE in Dhanalakshmi Srinivasan Engineering College, Perambalur, Tamilnadu. She completed her M.E VLSI Design in M.Kumarasamy College of Engineering, Karur, Tamilnadu. Her research interests are VLSI signal processing, Network on Chip.

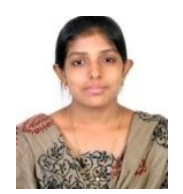

V.Subashini, Assistant Professor of Department of ECE in K.Ramakrishnan College of Engineering. She completed her B.E in ECE Department at Panimalar Engineering College. She completed her M.E in Applied Electronics at SSN College of Engineering. Her Research Interests are VLSI Design. 